\title{
* HEREDITARY FACTORS IN LEPROSY
}

ERNST KEIL.

Until a few years ago infectious diseases, under the impress of the great discoveries of the bacteriological era, were looked upon almost exclusively as the result of contagion. It is certainly true that in leprosy the presence of Hansen's bacillus is essential to the existence of a lesion, yet the epidemiology of leprosy clearly demonstrates that mere exposure to infection is not an all-powerful factor in the genesis of the disease, since the number of individuals so exposed who escape the consequences is so great that its significance cannot be disregarded. It is now known that the most adult persons, even when permanently in the most intimate contact with lepers, remain free from the disease, and it is sufficient to recall that doctors, nurses and even matrimonial partners, notwithstanding very heavy daily exposure, rarely become infected.

In the past decade the attention of investigators of this problem has been more especially directed to the sum total of the agencies which, apart from the externally-acting leprous virus, affect the organism and promote the development of a leprous lesion.

* The original article appeared in the Arch für Schiffs und Trop. Hyg. 43-3, 1939; the author has sent in this English translation for publication. 
Although the multitude of manifestations makes an assured classification of the extremely complex environment influences very difficult, enquiry into such possible harmful factors as defective nourishment, conditions of life, secondary infections and so forth shows that these may have far-reaching effects upon the visible aspect and spread of leprosy (Rogers and Muir). It is, for instance, generally recognised to-day that the mortality of leprosy falls as soon as the standard of life in the community is raised.

The naturally-constituted counteracting forces, and the principles of heredity associated with these, are of great importance for the progress of a- leprous infection; for we know that variability of resistance imposes a certain selectivity of attack, although probably the entire human race is susceptible to invasion by the Hansen bacillus. Daily observation shows that, while many persons, both young and old, when exposed to infection are receptive to the bacillus, yet only few of them contract the disease. The widespread receptivity to the infective organism suggests an analogy with diphtheria where, as a rule, such receptivity leads to the creation of the " carrier" class and comparatively seldom to the clinical event. Predisposition, which forms part of " constitution," explains why the body, when exposed to the infection of a given disease, contracts that disease with more than average probability. Thus, in relation to the general susceptibility of mankind to leprosy, predisposition would seem to indicate something accessory, enhancing, and provocative of the phenomenon of leprosy. This constitutional, individual factor is, in part at least, based upon one or more hereditary peculiarities. These peculiarities, though scarcely responsible for the actual colonisation of the leprosy bacillus, may well exert a wide and even decisive influence on the individual features of the disease, such as the mildness or severity of its course.

As early as the middle of last century leprologists believed that leprosy might have a hereditary basis. At that time the theory which had already been founded at an even earlier date, derived its chief support from the writings of Danielsson and Boeck (I848). These investigators regarded the family group-incidence of leprosy shown in statistics not as the consequence of inter-family infection, but as a manifestation of a hereditary disease transmitted from one human being to another. Among those who held this view of leprosy were Virchow, Babes, Blaschko and Jeanselme, and it remained valid until the 'seventies of last century, when it was relegated to the background by the convincing evidence of bacteriology and epidemiology. Since then there have only been isolated references to the relations of constitution and bloodgrouping to leprosy (Süäsk, Suzue and Kawarura, Aoki). The 
investigations of Diehl and v.Verschuer, however, have again directed attention to the significance of a hereditary basis for the genesis and progress of infectious diseases. With the aid of research on twin-births these investigators have shown that underlying the aetiology of tuberculosis, a disease recognised as resembling leprosy in many respects, there is a recessively inheritable predisposition which has a clinical manifestation probably of about 80 per cent.

Research on twin-birth has lately acquired increasing importance in the study of individual predisposition based on the principles of heredity. By its aid is now being sought (I) to furnish proof of a specific inheritable predisposition, (2) to evaluate the probability of manifestation of this predisposition, and (3) to discover the effect of peristasis. To gain an insight into what happens biologically in heredity, twin-birth research compares two human groups distinguished from one another solely by dissimilarity of determinant factors. By the keeping of statistical records of twin born from one ovum or from two, it can be ascertained how often a given disease will be found to attack both or one of the pair. The former event is referred to as concordant, the latter as discordant, behaviour. The principle of the comparison is based on the fact that every inheritable disease is encountered more frequently shared in identical (i.e. uniovulary) than in non-identical twins, and again in the latter more often than in subjects not of one family. The concordancefrequency of uniovular twins is, without exception, greater than in biovular twins, and the latter, being non-identical, differ therefore in the same way as ordinary members of a family in certain hereditary factors. The inheritable characteristics of biovular twins must therefore naturally differ more often. The bi-partite uniovular twins must possess identical predispositions, and to this is to be attributed the remarkable similarity of structure, appearance, and vital manifestations of twins born from one ovum.

If an inheritable natural tendency is an essential factor in the genesis of and resistance to leprosy, then we might expect not only a greater but also a far more frequent correspondence of the phenomena associated with leprosy in uniovular than in biovular twins. A concordance in uniovular twins as applied to leprosy, particularly if environmental discordance coexisted, might therefore be looked upon as clear proof for an inheritable predisposition to the disease. The possible courses taken by an infection in uniovular and biovular twins are (I) the disease might pursuc a more or less identical course in both twin-partners, (2) both partners might contract the disease but the clinical course would be different, or (3) one of the pair might contract the disease while the other remained healthy. 
The fundamental principle in research on twin-birth is an accurate diagnosis of uniovularity. The normal method of determining the hereditary equality of twin-pairs of the same sex is the poly-symptomatic parity method of Siemens and v.Verschuer. It is based on the resemblance, so close as often to arouse astonishment, existing between uniovular twins and the dissimilarity between those not uniovular. This external likeness, often photographically exact, can persist until advanced age even under varying environmental influences. In the polysymptomatic method of diagnosis the qualities taken into account are mainly those which in uniovular twins nearly always correspond, but in biovular twins seldom do so. Especially valuable is agreement in inheritable characteristics which peristatically are not variable, such, for instance, as the blood-group. The diagnosis should not of course rest on a few characteristics only, and although a certain amount of unreliability is found to exist in the estimation of uniovular twins, yet in practice the method yields results sufficiently trustworthy. Examination of the placenta and foetal membranes for proof of uniovularity is possible only in exceptional cases; moreover as even uniovular twins with identical predispositions can be born in separate membranes, the value of placental examination is doubtful.

The frequency of occurrence of twin-births varies, according to Diehl and v.Verschuer, in different latitudes, probably in accordance with racial differences, climatic influences, etc. As a generalisation it may be said that proportionately more twins are born in cool than in hot countries; although no statistical record of twin-births in Surinam has been compiled as yet, my enquiries appear to confirm the truth of this statement, for the number is smaller there than, for instance, in Germany. In Surinam the proportion is I-I36, while in Germany, according to Diehl and v.Verschuer, it is $\mathrm{I}-85$. About 30 per cent of twins born in Germany are uniovular (v.Verschuer).

Among about 400 patients in the Leprosy Polyclinic at Paramaribo five pairs of twins (Nos. I-5) were found. In Cases I and 2 both twin-partners proved to be leprous, in Case 3 only the one partner.

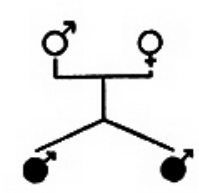

Case No. 1.

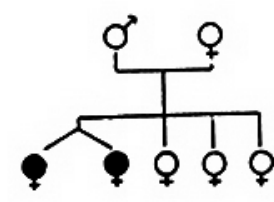

Case No. 2.

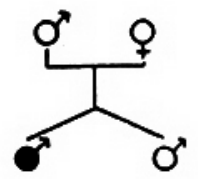

Case No. 3. 
Case 4 shows twins of whom both were free from leprosy, but who lived permanently with two cases of early leprosy in members of the same family. In Case 5 the mother of the twins was leprous, but they themselves were free from the disease. Another two pairs of twins were to be found (Nos. 6 and 7) among the 550 patients in the Surinam leper colonies; in Case 6 one partner was leprous, while in Case No. 7 both partners were diseased.

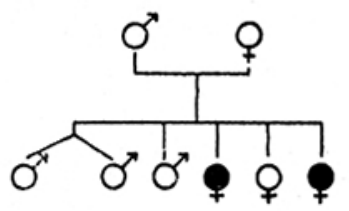

Case No. \&.

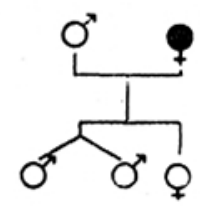

Case No. 5 .

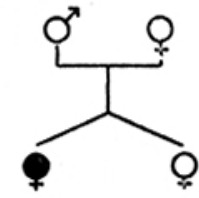

Case No. 6.

Since uniovularity could not be determined with certainty on external grounds in the twin-pairs of the same sex up to Case 7 , their description can be passed over. Case 7, however, illustrates the opportunities for observation offered in the investigation of leprosy in twins.

Case No. 7. Twin-pair N. Creoles, born in Paramaribo in 1905. On the mother's side of the family no occurrence of leprosy could be traced. She had five healthy children by a man other than the father of the twins.

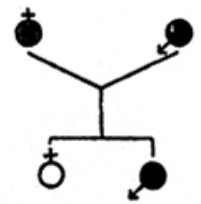

Case No. 7.

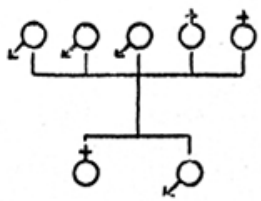

Case No. 8.

Three years after the birth of the latter the father died in a Surinam leper colony, of a severe type of nodular leprosy from which he had suffered for several years. While the female twin had been sent to live with the maternal grandmother, the male had remained with the mother, though the brother and sister had frequent opportunities of meeting. Of contact with lepers, particularly with their father in the leper colony, nothing certain could be ascertained. The first signs of disease were seen in the female at the age of 7 , in the form of patches on both cheeks, and in the boy at the age of II, of patches on the right gluteal region. In both the patches increased in number and extent as the years went on. Hyperaesthetic and, later, anaesthetic areas, thickening of the ulnar nerve, and other nervous symptoms made their appearance at the same rate and at much the same time in both 
patients. About the year I930 both began to develop muscleatrophy and contractures. of the fingers; at the time of the last examination in 1935 both showed definite atrophy of the thenar and hypothenar muscles and interossei, with deformities of the terminal phalanges, contracted position of the fingers, and claw hand. In the male there was also a left-sided facial paresis and abduction of the thumbs. Both patients were consistently bacteriologically negative. They now exhibit the picture of Lepra nervosa in the third stage. The course of the disease is obviously highly concordant.

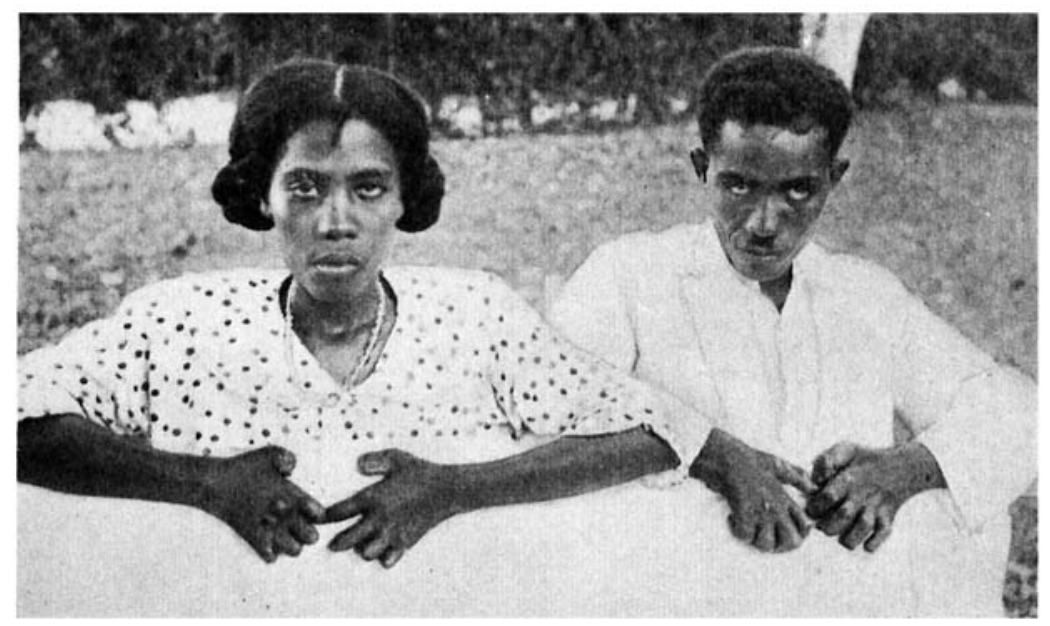

Twin-birth investigation needs to be supplemented by methodical family research; for comparison between healthy and diseased members of a family can also contribute to disclose the significance of heredity where exposure to infection is sufficiently equalised as to lie within a safe margin of probability. Leprosy, like tuberculosis, is not merely a disease of isolated individuals, but, even if at times subject to great oscillations, can frequently be traced in the same family for generations. The familiar grouping of leprosy cases in families can certainly be attributed, in part at least, to increased intrafamilial exposure due to the greater bacillary dissemination, and also to the concentration of other environmental influences shared in common. Yet the remarkable fact remains that, in spite of equality of surrounding conditions within a family, different degress of susceptibility to leprosy infection obviously exist. Under the primitive conditions of life obtaining in leper countries all children in a leper family are fairly uniformly exposed to infection, since for months and years they often share the same room and even the same bed with the diseased; in spite of this, however, by no means all 
children contract leprosy. The high incidence of leprosy in the ascendancy of certain tribes also points to the fact that the genesis of leprosy is favoured by factors which do not have their origin in environment. It might be thought that the inability for immunisaiion also occurs in family groups. We know that the children of leprous parents, owing to a certain lack of vigour, are attacked by other infectious diseases more often than children of similar age belonging to the healthy population (Hopkins, v.Duering), and the supposition is that the greater mortality from leprosy among descendants of leper families is also connected with this circumstance (Aycock and McKinley). In leper families those persons are usually attacked who resemble the leprous member, while those who do not resemble them are able to resist the disease. Human beings who resemble one another in both physical and psychical respects, such, for instance, as parents and children, are known to exhibit similar pictures in illness under approximately similar outward and inward circumstances; in the same way it may happen that within a family circle leprosy takes a course which is peculiar to that family. An example of this is shown in Case 8 (Majella Leper Colony at Paramaribo) where all the five members diagnosed as leprous developed in the course of years a uniformly pure type of nervous leprosy.

Tisseuil describes eight cases of familial leprosy in which the course of the disease in parents and children was strikingly similar. The clearly shown tendency of leprosy to attack certain organs in members of the same family has given rise to the assumption of a familial organic predisposition. In one case observed by Gougerot and Ruppet the leprous skin lesions of father and son were so alike as to appear " traced "; both suffered from the maculo-anaesthetic type. Jordan also describes in father and son a close resemblance in type and extent of maculo-anaesthetic leprous foci. This agreement in localisation could be interpreted as implying that inheritance of specific qualities in the terrain is

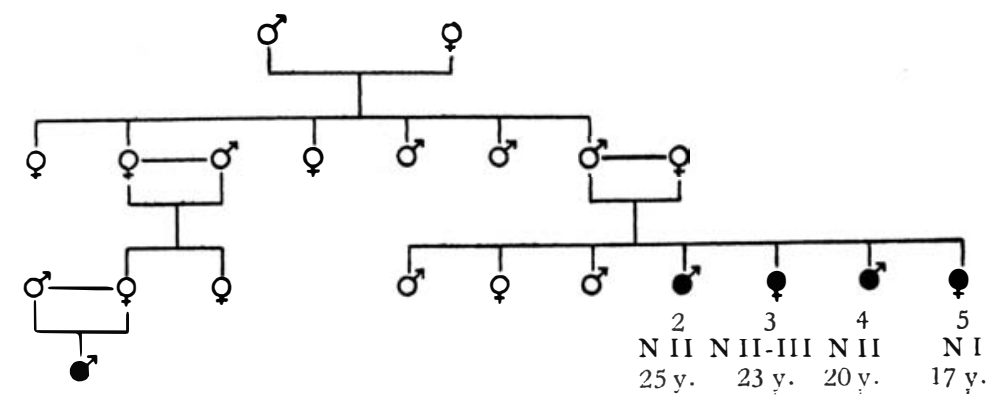

N I 8 years

Case No. 8, 
possible, and that in some circumstances a localised predisposition to attack by the leprosy bacillus can be inherited.

It is essential for research on heredity in leprosy that the greatest possible number of characteristic cases of twin-pairs and the genealogical trees of leprous families should be assembled. The greater the number of investigations included in the statistical matter the less will be the error inherent in the small number. The study, extending as far back as possible, of blood-related families should take stock not only of descent in the direct line but of collateral descent also. Of particular value are twin pairs the partners of which grow up separated from one another under dissimilar surrounding conditions. Pairs from a leprous milieu, even if they themselves are free from leprosy, also come within the scope of the investigation. The cases should not be specially selected, neither in twin-birth nor family research, as a selected clinical material tends as a rule to collect in a leper colony. It may be mentioned that in compiling such statistical records the investigator often encounters a not unnatural opposition in the families concerned; tact and mutual understanding is therefore essential.

As stated earlier in this paper, the causal complex underlying leprosy is made up of exogenous, specific infective, and peristatic factors. How far the inheritable constitutional factor is involved remains an open question. There is much in support of the conjecture that in leprosy-as in tuberculosis-the infective organism, environment, and heredity stand in reciprocal relation to one another, and that in a given assemblage of factors each of these three primary factors can decide the issue and determine the course of the disease. So much is certain, that so complex a process as leprosy infection cannot be elucidated by exploration of a single avenue; only by scrutiny of the event as a whole can we safeguard ourselves against giving undue weight to the one or the other possibility. An understanding of the aetiological dynamic of leprosy would be very greatly advanced, if the share of each of the three primary factors could be exactly estimated, and the principal and secondary causes ascertained in individual cases. It would seem that research on heredity, and particularly on twin-birth, can thus furnish a valuable contribution to knowledge of the aetiology and pathology of leprosy. The study of the question whether individual hereditary predisposition is an underlying factor in the disease will assist an understanding of the occurrence of leprosy in its individual determinants. To stimulate this study, in default of the possibility of further work by the present writer, is the main purpose of this paper. 


\section{LITERATURE.}

Aycock and McKinley: Internat. Jour. of Leprosy 1938, Vol. 6, No. 2. Babes, quoted by Klingmueller: Handb.d.Haut-und Geschlechtskr., Io/2, p.203.

Blaschko: quoted by Klingmueller (p.203 supra).

Danielssen and Boeck: Traité de la Spedalskhed ou Elephantiasis de Grecs ( 1848 ).

Diehl and v.Verschuer: Zwillingstuberculose "( 1933 ).

Diehl and v.Verschuer: Der Erbeinfluss bei der Tuberculose (r936).

v.Duehring, quoted by Klingmueller: (p.196 supra).

Gougerot and Ruppett: Bul. Soc. franc. Dermat. I92 I, 398.

Hopkins, quoted by Klingmueller: (p.203 supra).

Jeanselme, quoted by Klingmueller: (p.203 supra).

Jordan: Arch.f.Dermatol.u.Syphil. Vol. I70, I934.

Rogers and Muir: Leprosy (I925).

Saäsk, Suzue and Kawamura, Aoki, quoted by Klingmueller:

Zentralbl.f.Haut-u.Geschlechtskr. Vol. 57, Nos. 5 and 6, pp.353, 358.

Siemens: Zwillingspathologie ( I924).

Tisseuil: Bull. Soc. Path. exoth. Paris 1929, 63I, XXII.

Virchow, quoted by Klingmueller: (p.203 supra). 